EDITORIAL

\title{
Dos nuevas secciones en la Revista.
}

Iniciamos en este número dos nuevas secciones en la Revista. Su intención básica es seguir incluyendo diferentes áreas de interés y ampliar así las perspectivas de la misma. Todo ello intentando llevarlo a cabo desde una postura distendida, aunque nunca exenta de rigor y erudición.

La primera de estas secciones será "Historias con Historia" donde, como su nombre sugiere, tendrán cabida toda una serie de documentos de interés histórico que, sin la solemnidad ni extensión de las obras recogidas en los libros de la "Colección Historia" de la AEN, sin embargo sean merecedores de ser rescatados de los cajones en que quedaron archivados.

Principalmente serán breves textos de interés para nuestra historia psiquiátrica particular, intentando igualmente que las obritas "rescatadas" sean curiosas, entretenidas, o especialmente relevantes por cualquier otro motivo. No tendrán porque ser únicamente trabajos clínicos o académicos, sino también divulgativos, artículos periodísticos u otras producciones institucionales o de los propios pacientes.

Cada escrito seleccionado para su reimpresión irá precedido de un breve escrito introductorio que lo contextualice, bien en la época y circunstancias sociopolíticas que le rodeaban, o en cualquier otro aspecto por el que pudiera resultar interesante o reseñable. Para esta tarea contaremos con la opinión autorizada de diferentes autores invitados, entre los que los miembros de la Sección de Historia de la AEN, interesados de excepción en el proyecto, tendrán un papel relevante.

La segunda de las secciones, recogida bajo el sugerente título de "Boticarium", surge de la necesidad, largamente reconocida, de contar en la Revista con una sección a modo de revisión que se ocupe de una forma crítica y lo más independiente posible de los aspectos farmacológicos de nuestra práctica asistencial. No descartando futuras colaboraciones, de entrada contaremos con el compromiso para llevarlo a cabo de Juan Medrano que, a la consistencia formal de los contenidos, sabrá dar ligereza verbal en su tono habitual. Es decir, el estilo con el que él mismo explica la ambición de la sección:

Los comentarios recogidos en "Boticarium", tendrán la humilde pretensión de comunicar novedades en el ámbito de la Psicofarmacología, huyendo del tono triunfalista habitual. Raro será que informemos sobre triunfantes ensayos clínicos en los que el producto " $\mathrm{A}$ " gana por goleada al placebo (entre otras cosas, porque a veces, todo hay que decirlo, es por la mínima, en el tiempo de descuento y gracias a un penalti dudoso o a un gol fantasma). Tampoco merecerá nuestra atención, en principio, la quincuagésima indicación autorizada del producto "B". La intención 
es más bien ofrecer una visión razonadamente crítica, por una parte, pero esforzadamente ponderada, por otra, de informaciones que consideramos de interés, ya sea porque pueden orientar a un uso más prudente de los medicamentos, ya porque socavan amistosamente los cimientos de esa la práctica psiquiátrica contemporánea, pretendidamente biológica, pero esencialmente farmacológica. La selección y los puntos de vista expresados son, por supuesto, responsabilidad única y exclusiva del autor, con la única salvedad de que tenderemos a recoger siempre que sea posible artículos a cuyo texto completo pueda accederse en Internet.

Por último, simplemente señalar que aunque intentaremos dar la mayor continuidad posible al proyecto, como con el resto de secciones, las dos que hoy incorporamos no tendrán por que estar presentes en cada uno de los números publicados, de igual forma que quedan también abiertas a posibles contribuciones por parte de los lectores de la Revista.

O.M.A. 